Article

\title{
Application of Artificial Neural Networks to Assess the Mycological State of Bulk Stored Rapeseeds
}

\author{
Jolanta Wawrzyniak $(D)$ \\ Food Engineering Group, Department of Technology of Plant Origin Food, Faculty of Food Science and \\ Nutrition, Poznań University of Life Sciences, ul. Wojska Polskiego 31, 60-624 Poznań, Poland; \\ jolanta.wawrzyniak@up.poznan.pl
}

Received: 27 October 2020; Accepted: 20 November 2020; Published: 22 November 2020

\begin{abstract}
Artificial neural networks (ANNs) constitute a promising modeling approach that may be used in control systems for postharvest preservation and storage processes. The study investigated the ability of multilayer perceptron and radial-basis function ANNs to predict fungal population levels in bulk stored rapeseeds with various temperatures $\left(\mathrm{T}=12-30^{\circ} \mathrm{C}\right)$ and water activity in seeds $\left(a_{\mathrm{w}}=0.75-0.90\right)$. The neural network model input included $\mathrm{a}_{\mathrm{w}}$, temperature, and time, whilst the fungal population level was the model output. During the model construction, networks with a different number of hidden layer neurons and different configurations of activation functions in neurons of the hidden and output layers were examined. The best architecture was the multilayer perceptron ANN, in which the hyperbolic tangent function acted as an activation function in the hidden layer neurons, while the linear function was the activation function in the output layer neuron. The developed structure exhibits high prediction accuracy and high generalization capability. The model provided in the research may be readily incorporated into control systems for postharvest rapeseed preservation and storage as a support tool, which based on easily measurable on-line parameters can estimate the risk of fungal development and thus mycotoxin accumulation.
\end{abstract}

Keywords: rapeseed storage; mold growth; fungal contamination; predictive mycology; artificial neural networks; neural network model

\section{Introduction}

Rapeseed (Brassica napus L.) is one of the most important species among protein-oil crops grown in regions of moderate climates. The development of improved rapeseed varieties, i.e., free from harmful erucic acid and with a reduced glucosinolate content (the so-called double zero varieties " 00 "), has increased interest in this crop over the past decades. As a result, a significant increment in rapeseed cultivation has been observed and consequently, its world production has increased on average from 10.8 million tons in 1980 to 75.0 million tons in 2018. In the last years (2009-2018) the largest rapeseed producers included Canada (24.6\%), China (13.7\%), India (7.4\%), France (5.1\%), Germany $(7.3 \%)$, Australia (4.7\%), Poland (3.5\%) and the United Kingdom (3.3\%), (http://www.fao.org).

Rapeseed plays an essential role in global agriculture and constitutes an important crop for many industries. In the food industry, it is one of the main raw materials, and its usefulness results, among others, from the fact that it contains a high level of oil characterized by a favorable fatty acid composition. Rapeseed oil is also a rich source of bioactive components with pro-health properties [1-3], which opens the possibility of its use in functional food production. In addition to oil that is a part of a healthy human diet, rapeseed residue (after oil extraction) is also a high-protein alternative to other raw materials in animal nutrition.

Due to its structure and chemical composition rapeseed is a very sensitive raw material that can easily deteriorate; therefore, maintaining its high-quality for the food industry is not an easy task and 
requires proper seed treatment. As rapeseeds after harvest are usually stored before being processed, apart from ripening and harvesting conditions, postharvest seed treatment is of particular importance for their quality. It is known that improperly performed postharvest preservation and storage processes may contribute to undesirable changes in the rapeseed nutritional and technological quality, such as decreased seed germination, increased levels of free fatty acids, and the development of undesirable odors [3-6]. Inappropriate rapeseed postharvest treatment may also intensify oxidative processes and thus affect its composition [7]. One of the major problems during rapeseed preservation and storage is connected with seed contamination with filamentous fungi. Increased rapeseed moisture content (above $8 \%$ ) promotes mold activity in a mass of seeds even at low temperatures [6]. Fungal development in a bulk of rapeseeds may not only enhance the processes related to oxidation of fatty acids and other native biological compounds, but it may also result in the production of mycotoxins that can enter the human food chain through consumption of cooking oil or animal origin products (via feed produced from contaminated oil cake residues) [8].

The increasing rapeseed production requires appropriate postharvest seed treatment to minimize deterioration of their quality and to maintain food safety; therefore, the objective of modern agricultural postharvest management is to search for new effective control systems to preserve seed quality. Some studies on sensors designated to assess the level of mold contamination in seeds have been conducted using the e-nose technique or NIR hyperspectral imaging technique [5,9-11]. These techniques identify changes that have already occurred, but for manufacturers, it is more important to gain knowledge indicating hazards before they appear; therefore, in addition to the development of techniques signaling the fungal activity, prognostic tools need to be developed which in advance would provide predictions of the risk of mold growth and thus significantly improve postharvest management systems.

Predictive microbiology is based on knowledge of the nature of microbial development and it focuses mainly on mathematical models describing the impact of environmental factors on the kinetics of microbial growth. There are kinetic models describing changes in microbial populations in time under specific constant conditions (primary models), models describing dependences of the primary model parameters on environmental factors affecting microbial growth (secondary models), and models integrating primary and secondary models (tertiary models) describing fungal growth under dynamic conditions [12,13]. The most frequently used primary models of microbial growth are based on the modified Gompertz equation [14] and the Baranyi and Roberts equation [15]. The wide application of the above-mentioned kinetic models results from the fact that they follow a sigmoidal pattern reflecting typical microbial growth curves consisting of three characteristic phases, i.e., the lag phase (the phase without growth, being an adaptation of microorganisms to environmental conditions), the exponential growth phase (the phase of intensive microbial growth) and the stationary phase (the phase, being a state of ecosystem saturation with the microbial population). Nevertheless, the main advantage of used equations (similarity to the typical microorganism growth curve) may also be their drawback, as their use demands growth data covering all the three parts of the sigmoidal growth curve. This requirement makes it impossible to use the modified Gompertz and Baranyi and Roberts equations to model data obtained in experiments, in which microorganisms did not reach the third or the second and third phases of growth. Therefore, it is still worth looking for methods that do not require such far-reaching assumptions, particularly since the problem at the first stage of modeling (i.e., formulation of primary models) hinders the construction of secondary and tertiary models.

In recent years artificial neural networks (ANNs), which can describe nonlinear systems without prior requirements, have become an alternative to the existing kinetic models simulating microbiological growth. The structure and operation of artificial neural networks imitate the structure, signal flow, and transformation existing in the human nervous system. The basic units of the ANNs are neurons (nodes) arranged in a layer structure, in which neurons of the successive layers are connected by links of different weights. Neurons are equipped with activation functions, which enable them to perform calculations transforming input variables into output signals. 
In previous studies, ANNs were used in food safety and quality assessment to develop a computer vision technology providing its classification ability based on recorded images (via color, shape, and texture inspection) [16-21]. A combination of ANNs with measurement of volatile compounds, or with analysis of infrared or near-infrared spectra to evaluate the microbial state of food products was also undertaken [22-24]. Recently, in prognostic microbiology, attempts have also been made to apply tools using ANNs to assess the risk of microbial development based on environmental conditions. As emphasized by Jeyamkondan et al. [25], ANNs are robust and have the inherent ability to deal with high biological variability and the uncertainty related to microorganism growth; therefore, they may potentially be used to model dynamic microbiological systems. The application of ANNs in the predictive modeling of microorganism growth under various physical and chemical conditions has been previously reported in several papers [25-31]. Nevertheless, most studies focus on the description of bacterial growth and it is usually done under ideal laboratory conditions. Predicting modeling of filamentous fungi development with the use of neural networks has received much less attention to date. To our knowledge, only very few studies have considered the use of a neural network to model mold growth. Panagou et al. [32] and Panagou and Kodogiannis [33] developed ANN models to estimate the maximum specific growth rate of Monascus ruber and demonstrated that neural network architectures provided better predictions than the classical polynomial secondary models formulated as a function of temperature (T), water activity $\left(\mathrm{a}_{\mathrm{w}}\right)$ and $\mathrm{pH}$. The usefulness of multilayer perceptron (MLP) and radial basis function (RBF) networks to estimate ochratoxin A concentration over time in grape-based cultures of Aspergillus carbonarius under different conditions of temperature, water activity, and various doses of the fungicide carbendazim was proved by Mateo et al. [34]. Promising results were also demonstrated for the prediction of deoxynivalenol levels in the grain of barley contaminated with Fusarium culmorum [35].

It is worth emphasizing that even the best modeling techniques will not be effective if it is not based on accurate data. A key assumption when developing prognostic tools for postharvest systems is that they should be constructed on data taken from experiments carried out in ecosystems as close as possible to real ones. The lack of actual data encompassing the entire range of conditions being of producers' interest is one of the most important shortcomings in the development of such tools [12]. Admittedly, broth-based models or growth models of individual fungal species on cereal matrices developed based on data obtained under ideal laboratory conditions (on Petri dishes instead of a bulk of seeds) have been widely described in the literature [32,33,36-38]. However, their application as prognostic tools for the real food systems is not reliable, as models obtained under arbitrarily modified experimental conditions may not accurately reflect fungal growth in actual systems [39-41]. In the case of stored rapeseed, the gap in reliable data that can be used while modeling is filled with results obtained by Wawrzyniak et al. [6] describing dynamics of fungal development in a bulk of seeds stored over a wide range of temperature and water activity in seeds. The availability of data reflecting the actual conditions that may be found in a stored mass of seeds, e.g., in a silo, provides grounds for an attempt to develop a model that could be used in postharvest systems. To our best knowledge, there are no studies regarding the application of artificial intelligence to forecasting the level of fungal infection in a mass of rapeseeds in relation to storage conditions; therefore, the object of this work is to study the ability of artificial neural networks to predict the level of fungal population in a bulk of rapeseeds stored under different temperature and humidity conditions.

\section{Materials and Methods}

\subsection{Experimental Data}

The experimental data were taken from the research by Wawrzyniak et al. [6], which investigated mold growth in rapeseed ecosystems with an initial level of fungal propagules reflecting the mycological state of seeds vegetated or harvested under adverse weather conditions. In that study, the long-term experiments (48-72 days depending on storage conditions) were carried out to examine the impact of 
various temperature $\left(T=12-30^{\circ} \mathrm{C}\right)$ and humidity conditions $\left(\mathrm{a}_{\mathrm{w}}=0.75-0.90\right)$ on mold development in ecosystems of stored rapeseeds. The temperature and water activity in seeds (i.e., equivalent of the adequate air relative humidity in inter-seed spaces at the equilibrium state (ERH), where ERH = $100 \times a_{w}, \%$ ) that were applied during storage experiments are presented in Table 1. Each of the sixteen storage experiments (conducted at a given temperature and humidity conditions) was performed in duplicate. During that time, samples of rapeseeds were taken systematically, and then to designate the level of mold contamination in seeds the number of colony-forming units of molds per $1 \mathrm{~g}$ of seeds (CFU g ${ }^{-1}$ of molds) was determined in triplicate.

Table 1. Storage conditions under which the experimental data describing the mold growth in rapeseed ecosystems were collected.

\begin{tabular}{ccc}
\hline \multirow{2}{*}{$\begin{array}{c}\text { Temperature } \\
\left({ }^{\circ} \mathbf{C}\right)\end{array}$} & \multicolumn{2}{c}{ Type of Experiments } \\
\cline { 2 - 3 } & $\begin{array}{c}\text { Model } \\
\text { Development }\end{array}$ & $\begin{array}{c}\text { Model } \\
\text { Validation }\end{array}$ \\
\cline { 2 - 3 } & \multicolumn{2}{c}{ Water Activity } \\
\hline \multirow{2}{*}{12} & 0.76 & \\
& 0.80 & 0.86 \\
& 0.90 & \\
\hline \multirow{2}{*}{18} & 0.76 & 0.80 \\
& 0.86 & \\
\hline \multirow{2}{*}{24} & 0.90 & 0.85 \\
& 0.75 & \\
& 0.81 & 0.80 \\
\hline
\end{tabular}

\subsection{Data Sets Used for Modeling}

The decimal logarithm of mean values of the colony-forming units of molds ( $\log (\mathrm{CFU})$, $\left.\log \left(\mathrm{cfu} \mathrm{g}^{-1}\right)\right)$ was used to model fungal contamination in stored seeds as a function of temperature, water activity, and time with the use of ANNs. During the model development, the CFU of molds through the whole lag-phase of fungal growth was assumed to be equal to the initial level.

To develop the neural network model of mold contamination $\left(\mathrm{NNM}_{\mathrm{MC}}\right)$ in a bulk of rapeseeds, the data collected during storage experiments (296 cases) were divided into three groups. The model was built on data obtained in twelve experiments ( 222 cases, from which 153 were used as training points and 69 as testing points), whilst data from the remaining four experiments (74 cases) was used for model validation. Consequently, the training, test, and validation data sets constituted 52, $23 \%$, and $25 \%$ of the entire experimental data set, respectively. The names of the individual datasets were consistent with the terminology used in the StatSoft software 13.3, i.e., the training data set was applied to network learning (training); the test data set attended in the network examination during the learning process and it interrupted this process when there was the threat of network over-fitting, and the validation data set that was not involved in the network construction process, but it participated in the final evaluation of the developed neural network. Data set naming conventions need to be underlined here, as in the machine learning literature the names of test and validation data sets are used interchangeably, which is a source of many misunderstandings.

\subsection{Neural Network Models of Mould Contamination}

Feedforward neural networks (in which data pass the subsequent layers only from the input through hidden layer(s) to the output layer), such as the multilayer perceptron (MLP) and radial 
basis function (RBF) networks, are the most commonly used in the food industry and chemical engineering $[27,33,34,42,43]$. In the above-mentioned network types, the neurons of the input layer convey independent variables through connections (with assigned specific weights) to neurons in the hidden layer. The neurons of the hidden layer transform the signals using the activation function and convey calculated values through connections (which also have assigned specific weights) to neurons in the output layer. In neuron(s) of the output layer, the signals are further processed by the activation function to form the final network responses. The main difference between the MLP and the RBF networks stems from its different learning strategies (global vs. local) [33], which follows from the properties of activation functions in the hidden layer neurons. In the case of MLP networks, neurons of the hidden layer usually contain a sigmoidal activation function (i.e., a logistic or hyperbolic tangents function), therefore a single neuron divides the points belonging to the space of independent variables into two groups and it is activated for points belonging to one group, while not being activated for points belonging to the other one (the so-called linear separation). In the case of RBF networks, the neurons of the hidden layer are assigned to specific points in the space of independent variables (the so-called activation center) and contain a radial activation function (usually a Gaussian function), therefore a single neuron is activated only within a small (defined by the parameters of the activation function) neighborhood of this point. As a result, in the case of MLP networks, a single input signal can activate several neurons and then all these activated neurons participate in the calculation of the network output, while in the case of RBF-based networks a single input signal usually activates a single neuron of the hidden layer and only the weight between the activated hidden and output neurons is used to compute the value of the network output. Another difference between MLP and RBF networks is that the MLP networks can include several hidden layers, while RBF networks are structures that always contain only a single hidden layer.

In the study, the MLP with a single layer and the RBF-based neural network were used to describe the dynamics of mold development in bulk stored rapeseeds. In both types of networks, the input layer was composed of three neurons, to which independent variables (water activity in seeds, temperature, and storage time) were assigned. The output layer was composed of a single neuron producing the network outcome in the form of predicted values of fungal population levels. The hidden layer structure was designated in the process of network architecture optimization. Networks with a different number of neurons in the hidden layer, ranging from two to sixteen for MLP networks and two to fifty for RBF networks, were tested in the process. Moreover, at this stage of neural network model development different configurations of activation functions in the hidden and the output layer neurons were examined (Table 2).

Table 2. Configurations of activation functions in the hidden and output layer neurons examined during the architecture optimization process of MLP and RBF neural networks describing mold contamination in rapeseed ecosystems with water activity $\mathrm{a}_{\mathrm{w}}=0.75-0.90$ stored at $12-30^{\circ} \mathrm{C}$.

\begin{tabular}{ccccc}
\hline & \multicolumn{4}{c}{ Activation Function } \\
\cline { 2 - 5 } $\begin{array}{c}\text { Type of } \\
\text { Network }\end{array}$ & Hidden Layer & \multicolumn{3}{c}{ Output Layer } \\
\cline { 3 - 5 } & & Linear & Logistic & $\begin{array}{c}\text { Hyperbolic } \\
\text { Tangent }\end{array}$ \\
\cline { 3 - 5 } MLP & Linear & Lin/Lin & Lin/Log & Lin/Tanh \\
& Logistic & Log/Lin & Log/Log & Log/Tanh \\
& Hyperbolic tangent & Tanh/Lin & Tanh/Log & Tanh/Tanh \\
RBF & Gaussian & Gau/Lin & - & - \\
\hline
\end{tabular}

For each size of the hidden layer and for each configuration of transfer functions in neurons of the hidden and output layers one thousand networks were generated. As a result, one hundred and thirty-five thousand networks (fifteen hidden layer sizes $\times$ nine configurations of activation functions (Table 2) $\times$ one thousand generated networks for each structure) were developed for MLP structures 
and forty-nine thousand networks for RBF-based structures. From every thousand networks generated for each topology, the top one hundred structures characterized by the lowest validation error were retained for further deliberations.

The general scheme for the architecture of the MLP and RBF neural networks that were used to develop the model of mold contamination in bulk stored rapeseeds is presented in Figure 1.

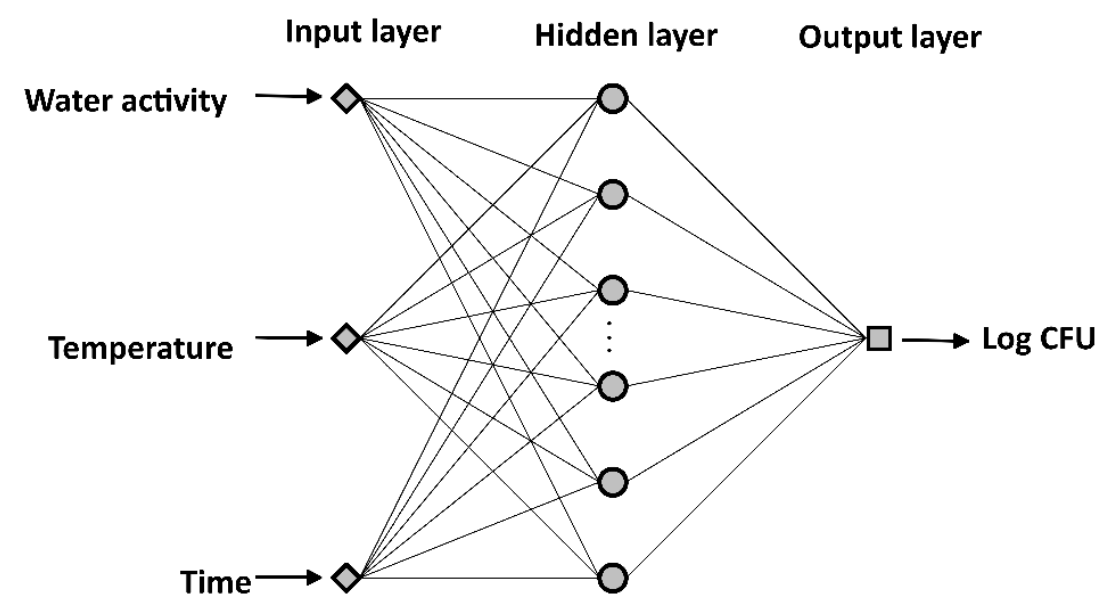

Figure 1. The schematic general architecture of multilayer perceptron (MLP) and radial basis function (RBF) neural networks used to develop the model of mold contamination in a bulk of rapeseeds with water activity $\mathrm{a}_{\mathrm{w}}=0.75-0.90$ stored at $12-30{ }^{\circ} \mathrm{C}$.

The network architectures were optimized during the training (learning), testing, and validation processes. The performance of each neural network in subsequent stages of model building was judged with the use of the sum-of-squares error function. The ANN training process consisted in an iterative modification of the strength of the connections between neurons of adjacent layers and modification of the parameters of activation functions. It aimed to minimize the training (learning) error $\left(\mathrm{E}_{1}\right)$ and it was conducted with the use of the training data set [42]. Simultaneously, to assess the correctness of the training process in each iteration the test error $\left(E_{t}\right)$ was calculated based on the test data set. The training process is usually carried out until the assumed number of iterations is reached, but it may be interrupted earlier if the training error stops decreasing or when the decreasing training error is accompanied by an increase in the test error, which usually indicates the network over-training. The neural networks may be trained by different algorithms, i.e., Levenberg-Marquardt (LM), Broyden-Fletcher-Goldfarb-Shanno (BFGS) and Genetic Algorithms (GA) as well as Reputation-based Byzantine Fault Tolerance (RBFT) [33,34,42,44]. In this study, iterative methods (training algorithms) dedicated to nonlinear optimization problems (StatSoft software 13.3) were used, such as the Broyden-Fletcher-Goldfarb-Shanno for MLP networks and Reputation-based Byzantine Fault Tolerance for RBF networks. Because the process of optimizing the network topology is considered successful only if the produced structure can perform well on data, on which the network has not been built [45], after its development the validation process was carried out. During this process conducted with the use of data obtained in independent experiments for each tested network, a validation error $\left(E_{V}\right)$ was computed to assess its generalization ability and capacity to work with new data. The artificial neural network modeling was carried out with the use of the neural network module being a part of the StatSoft software 13.3. The MLP and RBF networks that most effectively described changes in fungal population levels were adopted as the models of mold contamination in a bulk of rapeseeds. 


\subsection{Model Performance Assessment}

In the study, the statistical criteria recommended for the validation of prognostic models were employed to evaluate the performance of selected MLP and RBF neural network models and their practical suitability, $[25,46,47]$. The coefficient of determination $\left(R^{2}\right)$ was used to establish the fitting accuracy of the models. The average absolute deviation between predictions and observations was determined using the mean absolute error (MAE), whilst the goodness of fitting the predicted values to the experimental data was calculated by the root mean square error (RMSE). Bias indexes that inform on the mean divergence between the model predictions and experimental values included the mean relative percentage error $(\mathrm{MRPE}, \%)$ and the bias factor $\left(\mathrm{B}_{\mathrm{f}}\right)$ and were determined as follows:

$$
\begin{gathered}
\text { MRPE }=\frac{1}{n} \sum \frac{\log \left(\mathrm{CFU}_{\mathrm{E}}\right)-\log \left(\mathrm{CFU}_{\mathrm{M}}\right)}{\log \left(\mathrm{CFU}_{\mathrm{E}}\right)} \times 100 \\
\mathrm{~B}_{\mathrm{f}}=10^{\left(\sum \log \left(\frac{\log \left(\mathrm{CFU}_{\mathrm{M}}\right)}{\log \left(\mathrm{CFU}_{\mathrm{E}}\right)}\right) / \mathrm{n}\right)}
\end{gathered}
$$

where $\log \left(\mathrm{CFU}_{\mathrm{E}}\right)$ and $\log \left(\mathrm{CFU}_{\mathrm{M}}\right)$ are the experimental and modeled levels of mold contamination, respectively, and $\mathrm{n}$ is the number of observations. The absolute distance between estimations and observations was measured with accuracy indexes, i.e., the mean absolute relative percentage error (MAPE, \%) and an accuracy factor $\left(\mathrm{A}_{\mathrm{f}}\right)$ calculated with the following expression:

$$
\begin{gathered}
\text { MAPE }=\frac{1}{n} \sum\left|\frac{\log \left(\mathrm{CFU}_{\mathrm{E}}\right)-\log \left(\mathrm{CFU}_{\mathrm{M}}\right)}{\log \left(\mathrm{CFU}_{\mathrm{E}}\right)}\right| \times 100 \\
\mathrm{~A}_{\mathrm{f}}=10^{\left(\sum \log \left(\frac{\log \left(\mathrm{CFU}_{\mathrm{M}}\right)}{\log \left(\mathrm{CFU}_{\mathrm{E}}\right)}\right) \mid / \mathrm{n}\right)},
\end{gathered}
$$

\section{Results and Discussion}

\subsection{Neural Network Models of Mould Contamination}

Artificial neural networks are one of the most powerful modeling methods in solving engineering problems, particularly those associated with highly interconnected structures, in which various relationships occur and where there is no basis for linear approximation [25,42]. Due to their flexibility, high prediction accuracy, high generalization ability, and resistance to noisy data, the application of ANNs to model complex systems seems to be a promising approach $[26,48]$. As a bulk of rapeseeds is a dynamic multiplex ecosystem, in which a variety of non-linear interactions take place, in the study an attempt was made to apply ANNs to design a predictive model of mold development in a stored mass of seeds. For this purpose data covering a wide range of storage parameters that may be encountered in agricultural practice (i.e., from low values of water activity in seeds $\left(a_{w}=0.75\right)$ and low temperature $\left(\mathrm{T}=12{ }^{\circ} \mathrm{C}\right)$, at which seeds can be stored without considerable seed quality losses for a long time to very adverse conditions, i.e., high values of water activity in seeds $\left(a_{w}=0.90\right)$ and high temperature $\left(\mathrm{T}=30^{\circ} \mathrm{C}\right)$, at which lack of proper postharvest treatments almost immediately leads to seed quality deterioration $[1,3,6]$ ) were modeled using two approaches based on the neural network technique (MLP and RBF).

The capability of the network to approximate the analyzed data largely depends on the network structure, which includes among others the number of hidden layers (only in the case of MLP networks), the size of hidden layers, and the type of transfer function in hidden and output layer neurons. As it was emphasized by Panagou et al. [33], there are no rules that would clearly in advance indicate the topology of the neural network at the stage of its design. The most common way to optimize the network structure is a trial-and-error method [49], in which the process starts with a small and simple architecture and consists in adding new units when necessary. This is usually done empirically by comparing the results of each created structure to find the one with the best approximation capability. 
In the study, the optimal MLP and RBF network structures were found out iteratively by testing numerous architectures and observing their training, testing, and validation errors.

\subsubsection{Model Based on MLP Networks}

In the previous reports, various structures of neural networks were examined when modeling microbiological systems $[27,29,33,34]$. It was revealed that the use of the MLP containing a single hidden layer was usually sufficient for non-linear regression $[27,29,50]$. It is in agreement with Cybenko's theorem, according to which feedforward neural networks with a single hidden layer and a continuous sigmoidal activation function contained in neurons of this layer can approximate any continuous function on compact subsets within any level of precision [51]. In the study, the MLP neural network with a single hidden layer also turned out to be sufficiently good to model the mycological state of bulk stored rapeseeds.

The optimization process of a network structure (including the selection of the type of the activation function in neurons of the hidden and output layers and the size of the hidden layer) allowed us to determine the most suitable architectures for the MPL neural network model describing the mold population in rapeseed ecosystems. Among the tested MLP network architectures, the worst ones turned out to be those containing hidden layer neurons with a linear activation function. The mean values of training and test errors calculated for networks comprising a linear activation function in hidden layer neurons (regardless of the hidden layer size and a transfer function in the output layer neuron) did not change much and were in the range of $0.15-0.28$ and $0.10-0.22$ for the training and test errors, respectively. The relatively high levels of both these errors, together with high values of the mean validation error (0.18-0.29) disqualified the use of the above-mentioned architectures in the modeling of mold development. As a result, the network architectures that contained the linear transfer function in the hidden layer neurons were excluded from further deliberations.

For the other analyzed structures, the training and test errors were significantly lower and decreased with an increase in the number of neurons in the hidden layer (Figure 2). The greatest drop in mean values of training and test errors was observed for networks containing from two to eight neurons in the hidden layer. A further increase in hidden layer size (to nine and more neurons) changed the values of both errors within a narrow range only $(0.008-0.014$ for the training error and 0.011-0.018 for the test error). The downward trend in the training and test error values is because the networks with a small number of hidden neurons are too weak to map complex relationships [45], thus to increase its learning ability the hidden layer of larger size is required. Although for all network architectures retained for considerations the general trend in values of the above-mentioned errors was comparable, a thorough examination of Figure 2 showed that in the case of networks, in which the activation function in the output layer took the same form, the course of curves was the most similar to each other (regardless of the type of the activation function in the hidden layer neurons). The curves assigned to the networks with the same type of the transfer function in the output layer (Figure 2) formed groups indicating that the activation function in the neurons of the output layer has a greater impact on the training and test error values than the type of transfer function in the hidden layer neurons.

It is noteworthy that the network evaluation through the prism of training and testing errors only is insufficient and may lead to misleading conclusions. The over-trained networks are usually characterized by low training and test errors, but at the same time have poor generalization ability and are not capable of properly operating on the new data. The proper assessment of network performance should be based on the validation error that is a measure of network performance on data not used in model building. The influence of the hidden layer size and the type of transfer functions on the mean values of the validation error obtained for topologies considered in this study is illustrated in Figure 3. 

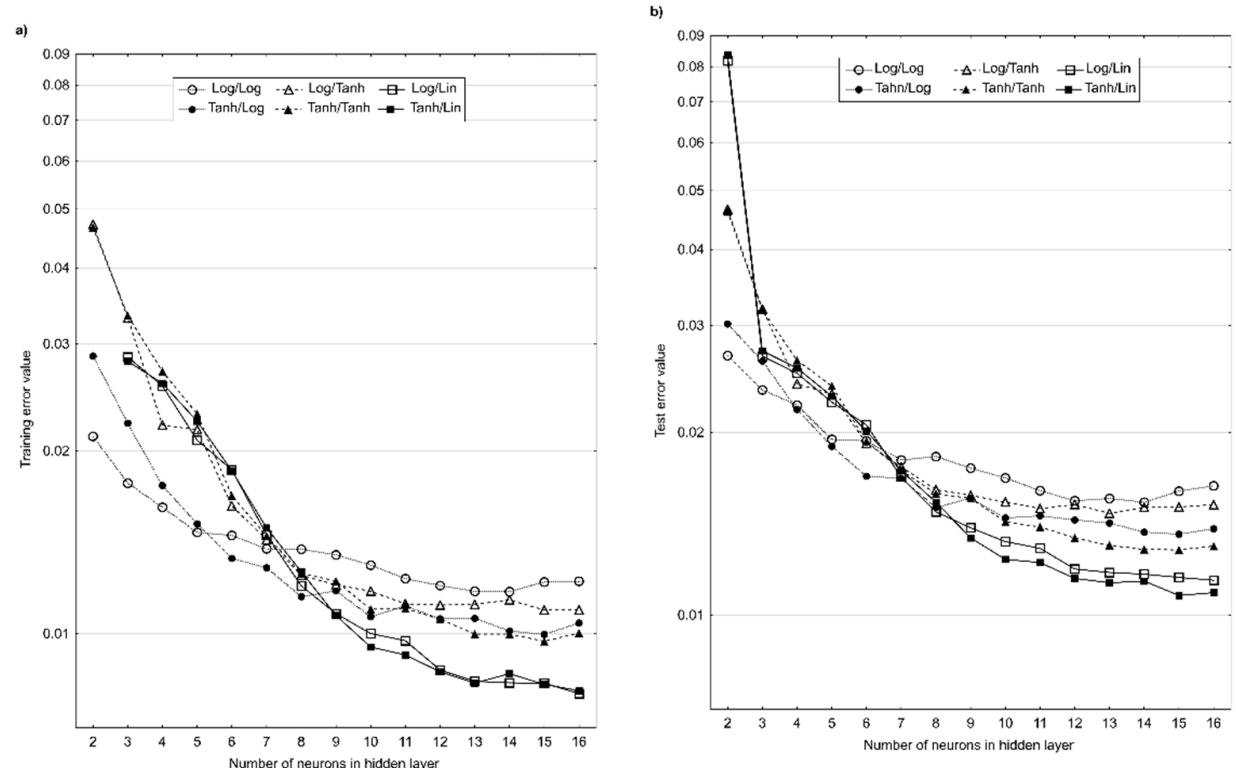

Figure 2. Changes in mean values of (a) training and (b) test errors of MLP networks applied to model mold contamination in a bulk of rapeseeds with water activity $\mathrm{a}_{\mathrm{w}}=0.75-0.90$ stored at $12-30{ }^{\circ} \mathrm{C}$ depending on the number of neurons in the hidden layer for each applied combination of activation functions (hyperbolic tangent (Tanh), logistic (Log), and linear (Lin)) in neurons of hidden and output layers).

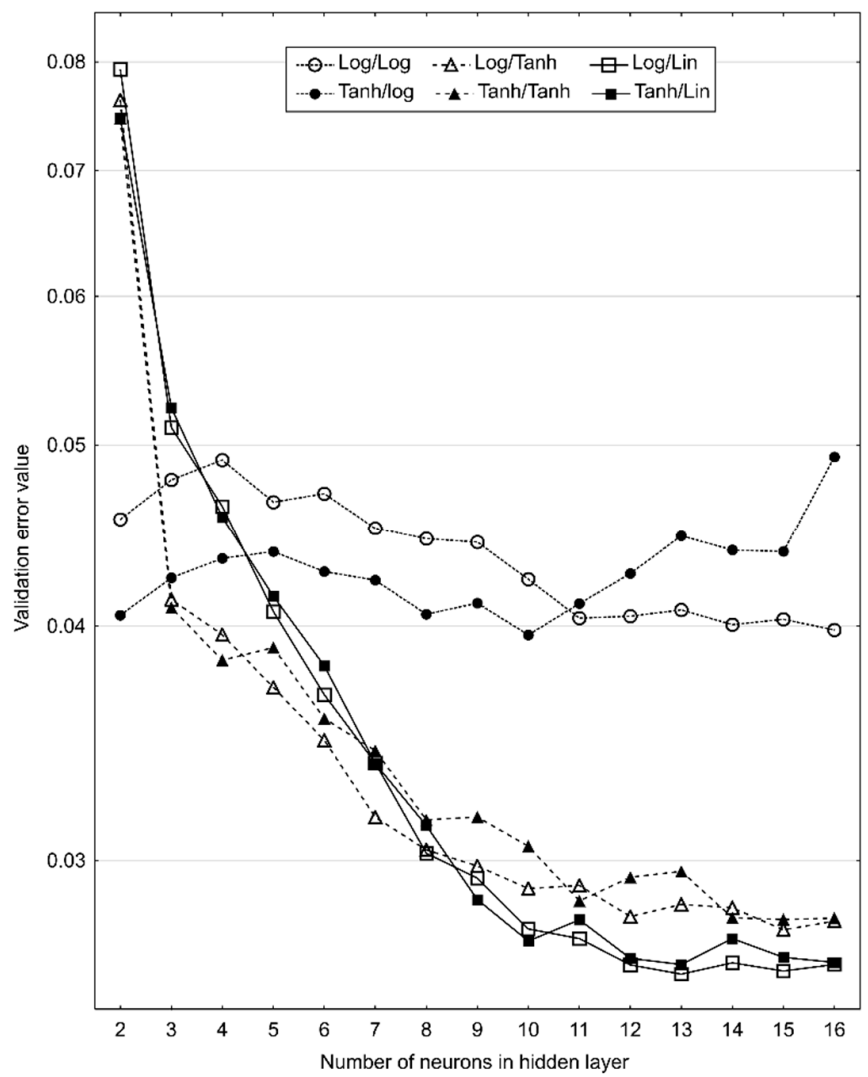

Figure 3. Changes in mean values of validation errors of MLP networks applied to model mold contamination in a bulk of rapeseeds with water activity $\mathrm{a}_{\mathrm{w}}=0.75-0.90$ stored at $12-30{ }^{\circ} \mathrm{C}$ depending on the number of neurons in the hidden layer for each applied combination of activation functions (hyperbolic tangent (Tanh), logistic (Log), and linear (Lin)) in neurons of the hidden and output layers). 
It is evident that for the examined architectures the impact of the type of activation functions in the output layer neurons on the level of the validation error is even greater than on values of the training and test errors. In the case of networks with the logistic function at the output, the values of the validation error changed to a limited extent and remained at a higher level (0.040-0.049) compared to the other tested topologies. Moreover, the validation error for networks with the Tanh/Log configuration of activation functions containing more than ten neurons in the hidden layer showed an upward trend, indicating overfitting of the data and their poor generalization ability [52]. Networks containing a hyperbolic tangent in the output layer neurons allowed to obtain better results, but even better outcomes were noted for topologies containing in neurons of the same layer the linear activation function. For these networks, an increase in the number of hidden neurons from two to twelve caused a substantial decrease in the value of the average validation error. A further increase in the number of neurons in the hidden layer (from thirteen to sixteen) did not have an essential impact on the values of the validation error (ranging from approximately 0.026-0.030).

The multilayer perceptron neural network, for which the sum of all errors $\left(E_{l}, E_{t}\right.$, and $\left.E_{v}\right)$ was the lowest was selected as the model of mold contamination in a bulk of stored rapeseeds (MLP-NNM $M_{M C}$ ). In the selected structure the hyperbolic tangent function acted as a transfer function in twelve neurons of the hidden layer, while the linear function acted as the transfer function in a single neuron of the output layer. The basic information on the MLP network adopted for the MLP-NNM $\mathrm{MC}_{\mathrm{MC}}$ obtained during the optimization process is presented in Table 3. The calculated values of the training, test, and validation errors indicated good predictive quality and generalization capability of the developed

Table 3. The basic information on the structure and training (learning) (El), test (Et), and validation (Ev) error values of MLP and RBF neural networks adopted as models of mold contamination in rapeseed ecosystems with water activity aw $=0.75-0.90$ stored at $12-30{ }^{\circ} \mathrm{C}$.

\begin{tabular}{ccccc}
\hline \multirow{2}{*}{$\begin{array}{c}\text { Architecture of Neural } \\
\text { Network Model }\end{array}$} & Activation Function & \multicolumn{3}{c}{ Errors } \\
\cline { 3 - 5 } & Hidden/Output Layer & $\mathbf{E}_{\mathbf{l}}$ & $\mathbf{E}_{\mathbf{t}}$ & $\mathbf{E}_{\mathbf{v}}$ \\
\hline MLP 3-12-1 & Tanh/Lin & 0.007 & 0.009 & 0.018 \\
RBF 3-30-1 & Gau/Lin & 0.039 & 0.032 & 0.055 \\
\hline
\end{tabular}

\subsubsection{Model Based on RBF Networks}

In the study, RBF networks with different numbers of the hidden layer neurons containing a Gaussian transfer function and one output node with the linear transfer function were considered to describe mold population levels in rapeseed ecosystems. The results of the optimization process for the RBF-based network architecture are presented in Figure 4. The increase in the number of neurons in the hidden layer from two to twenty nodes resulted in a considerable decrease in the mean values of the training and test errors in the range from 0.321 and 0.276 to 0.100 and 0.079 , respectively. Further extension of the size of the hidden layer caused a much slighter decline in values of these errors to 0.065 for the training one and 0.049 for the test one. In the case of the validation error, a downward trend in its mean value (from 0.23 to 0.071 ) was observed for networks containing from two to twenty-four neurons in the hidden layer. A further increase in the size of the hidden layer caused a decrease in the training and test errors, whereas the validation error had an upward trend. It is known that too many neurons in the hidden layer may lead to network overtraining and then the network, instead of generalizing dependencies existing in the modeled system, remembers the specific relationships between inputs and outputs, limiting its performance on new data [31,45]; therefore a substantial extension of the hidden layer size was not advisable. The conducted analyses show that the optimal structures for the RBF network to approximate mold infestation in rapeseed ecosystems were those that contained between twenty-four and thirty-four nodes in the hidden layer. For these structures, relatively low values of the validation error were accompanied by relatively low levels of the training and test errors. 


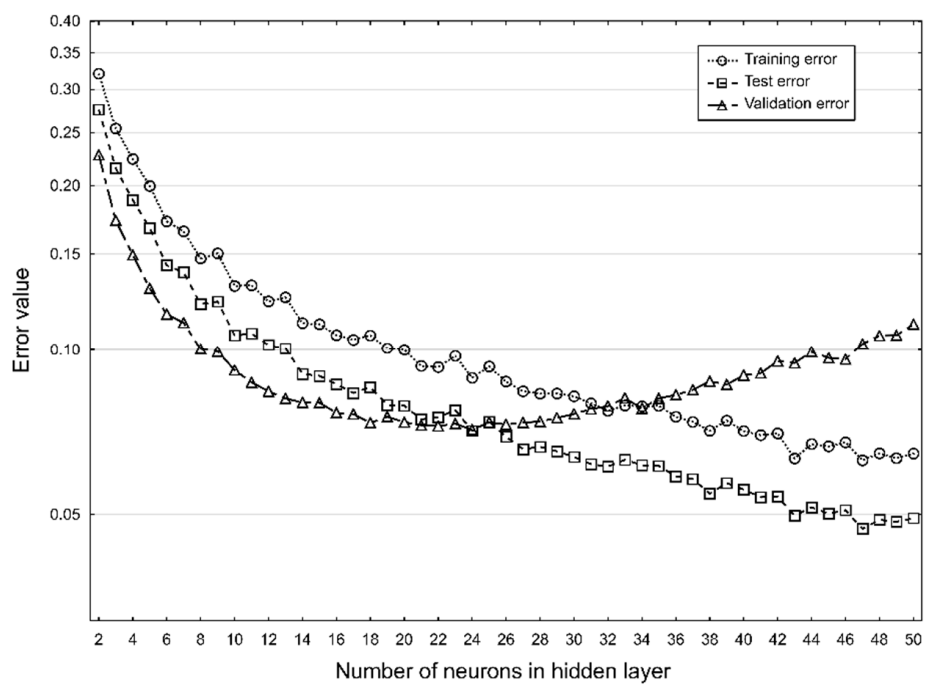

Figure 4. The effect of the number of neurons in the hidden layer on the mean values of training, test, and validation errors of RBF networks used to model mold contamination in a bulk of rapeseeds with water activity $\mathrm{a}_{\mathrm{w}}=0.75-0.90$ stored at $12-30{ }^{\circ} \mathrm{C}$.

The above-mentioned structures not only exhibited a balance between simplicity of architecture and quality of the network, but also provided reasonable prediction results. Among the built RBF networks, the one with the lowest sum of all errors was selected for the model of mold contamination $\left(\right.$ RBF-NNM $\left.\mathrm{MC}_{\mathrm{MC}}\right)$ in a bulk of rapeseeds. The selected structure comprised thirty nodes in the hidden layer with a Gaussian activation function and one output neuron with a linear activation function. The errors computed for the RBF-NNM $\mathrm{MC}_{\text {are summarized in Table } 3 .}$

\subsection{Model Performance Assessment}

Figures 5 and 6 illustrate the comparison of experimental data with the MLP-NNM $M_{M C}$ and the RBF-NNM $\mathrm{MC}_{\mathrm{MC}}$ predictions as a function of time. It is noticeable that there is a high agreement between MLP-NNM $M_{M C}$ responses and observed levels of fungal populations for all the data sets applied for model construction and validation. In the case of the RBF-NNM $\mathrm{MC}$, a lesser convergence of the model estimates with the observed data was found. For an accurate verification of the predictive and generalization abilities of the produced models, the MLP-NNM $\mathrm{MC}_{\mathrm{C}}$ and the RBF-NNM $\mathrm{MC}_{\mathrm{C}}$ were fully evaluated using indicators suggested for prognostic models $[25,46,47]$. The values of the statistical indexes used in the model assessment are listed in Table 4. The calculated RMSE and MAE values are considerably higher for the MLP-NNM $\mathrm{NC}_{\mathrm{MC}}$ than the RBF-NNM $\mathrm{NC}_{\mathrm{MC}}$ indicating better prediction capability of the MLP-NNM $\mathrm{MC}$.

Table 4. Statistical criteria used to evaluate the prediction accuracy of MLP and RBF neural network models of mold contamination in rapeseed ecosystems with water activity $\mathrm{a}_{\mathrm{w}}=0.75-0.90$ stored at $12-30{ }^{\circ} \mathrm{C}$.

\begin{tabular}{|c|c|c|c|c|c|}
\hline \multirow{2}{*}{ Statistical Index } & \multirow{2}{*}{$\begin{array}{c}\text { Type } \\
\text { of Model }\end{array}$} & \multicolumn{4}{|c|}{ Data Set } \\
\hline & & Training & Test & Validation & Full \\
\hline $\begin{array}{c}\text { Number of Observation } \\
\text { Points (N) }\end{array}$ & & 153 & 69 & 74 & 296 \\
\hline \multicolumn{6}{|c|}{ Fitting indicators } \\
\hline \multirow{2}{*}{$\begin{array}{c}\text { Coefficient of } \\
\text { determination }\left(\mathrm{R}^{2}\right)\end{array}$} & MLP & 0.99 & 0.99 & 0.97 & 0.99 \\
\hline & RBF & 0.96 & 0.97 & 0.89 & 0.95 \\
\hline \multirow{2}{*}{$\begin{array}{l}\text { Root mean square error } \\
\text { (RMSE) }\end{array}$} & MLP & 0.12 & 0.14 & 0.19 & 0.14 \\
\hline & RBF & 0.28 & 0.25 & 0.33 & 0.29 \\
\hline \multirow{2}{*}{$\begin{array}{l}\text { Mean absolute error } \\
\text { (MAE) }\end{array}$} & MLP & 0.08 & 0.09 & 0.14 & 0.10 \\
\hline & RBF & 0.20 & 0.17 & 0.26 & 0.21 \\
\hline
\end{tabular}


Table 4. Cont.

\begin{tabular}{cccccc}
\hline \multirow{2}{*}{ Statistical Index } & \multirow{2}{*}{$\begin{array}{c}\text { Type } \\
\text { of Model }\end{array}$} & \multicolumn{5}{c}{ Data Set } \\
\cline { 3 - 6 } & \multicolumn{2}{c}{ Training } & Test & Validation & Full \\
\hline & Bias indexes & & & \\
\hline Bias factor $\left(\mathrm{B}_{\mathrm{f}}\right)$ & RBF & 1.00 & 1.00 & 0.99 & 1.00 \\
& MLP & -0.14 & -0.06 & 1.25 & 0.24 \\
\hline $\begin{array}{c}\text { Mean relative percentage } \\
\text { error (MRPE), }(\%)\end{array}$ & RBF & 0.00 & -0.15 & -0.27 & 0.09 \\
\hline & Accuracy indexes & & & \\
\hline Accuracy factor $\left(\mathrm{A}_{\mathrm{f}}\right)$ & MLP & 1.01 & 1.02 & 1.03 & 1.02 \\
& RBF & 1.03 & 1.03 & 1.05 & 1.04 \\
\hline $\begin{array}{c}\text { Mean absolute percentage } \\
\text { error (MAPE), }(\%)\end{array}$ & MLP & 1.45 & 1.55 & 2.53 & 1.74 \\
\hline & RBF & 3.26 & 2.75 & 4.66 & 3.49 \\
\hline
\end{tabular}
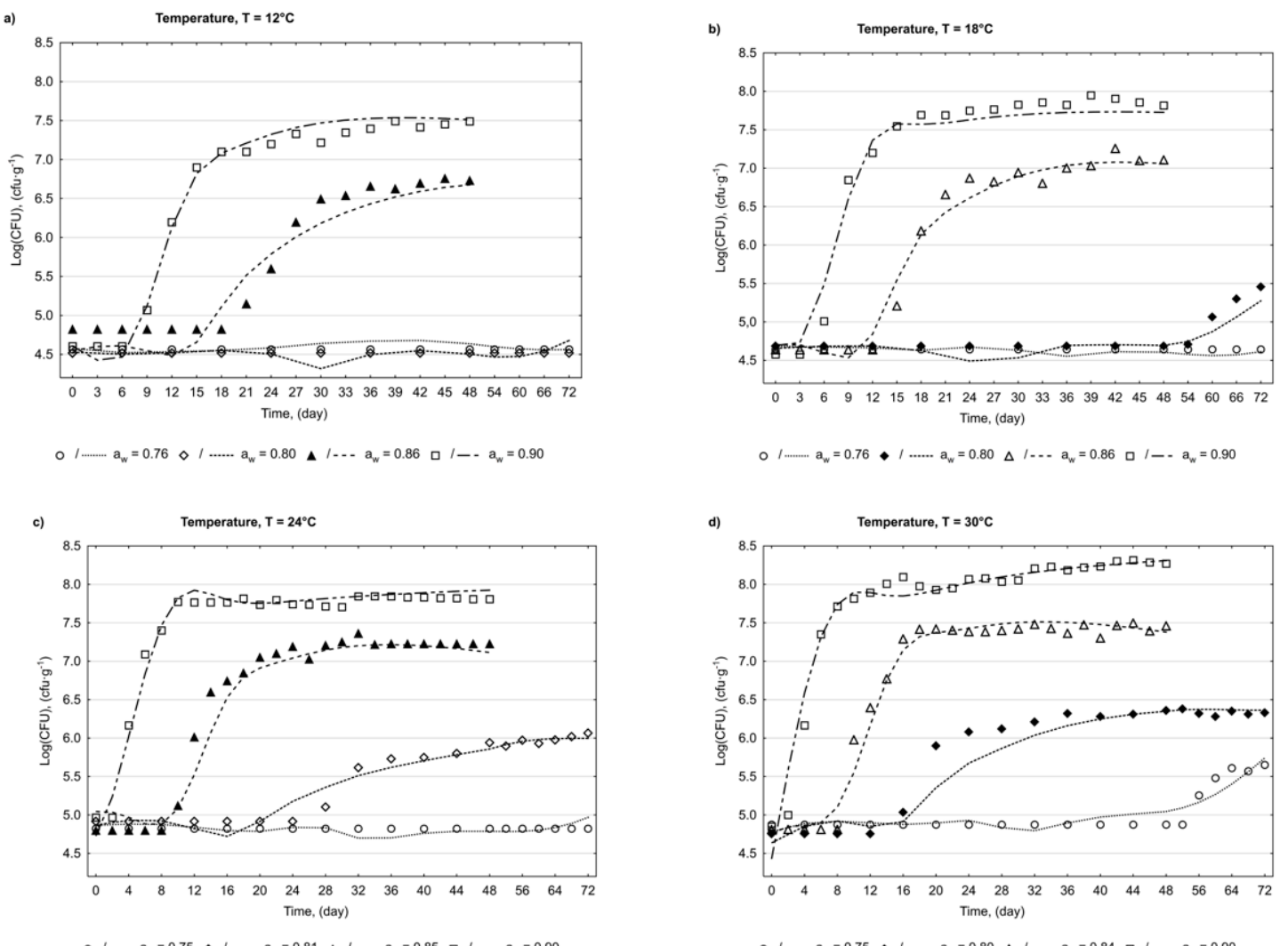

Figure 5. The comparison of MLP neural network model predictions (model lines) and observed mold population levels $(\log (\mathrm{CFU}))$ (experimental points) in rapeseed ecosystems with water activity $\mathrm{a}_{\mathrm{w}}=$ 0.75-0.90 stored at: (a) $12{ }^{\circ} \mathrm{C}$, (b) $18{ }^{\circ} \mathrm{C}$, (c) $24{ }^{\circ} \mathrm{C}$, (d) $30^{\circ} \mathrm{C}$ adopted from Wawrzyniak et al. [6] as a function of time (empty points - data used to model construction, filled points - validation data sets). 

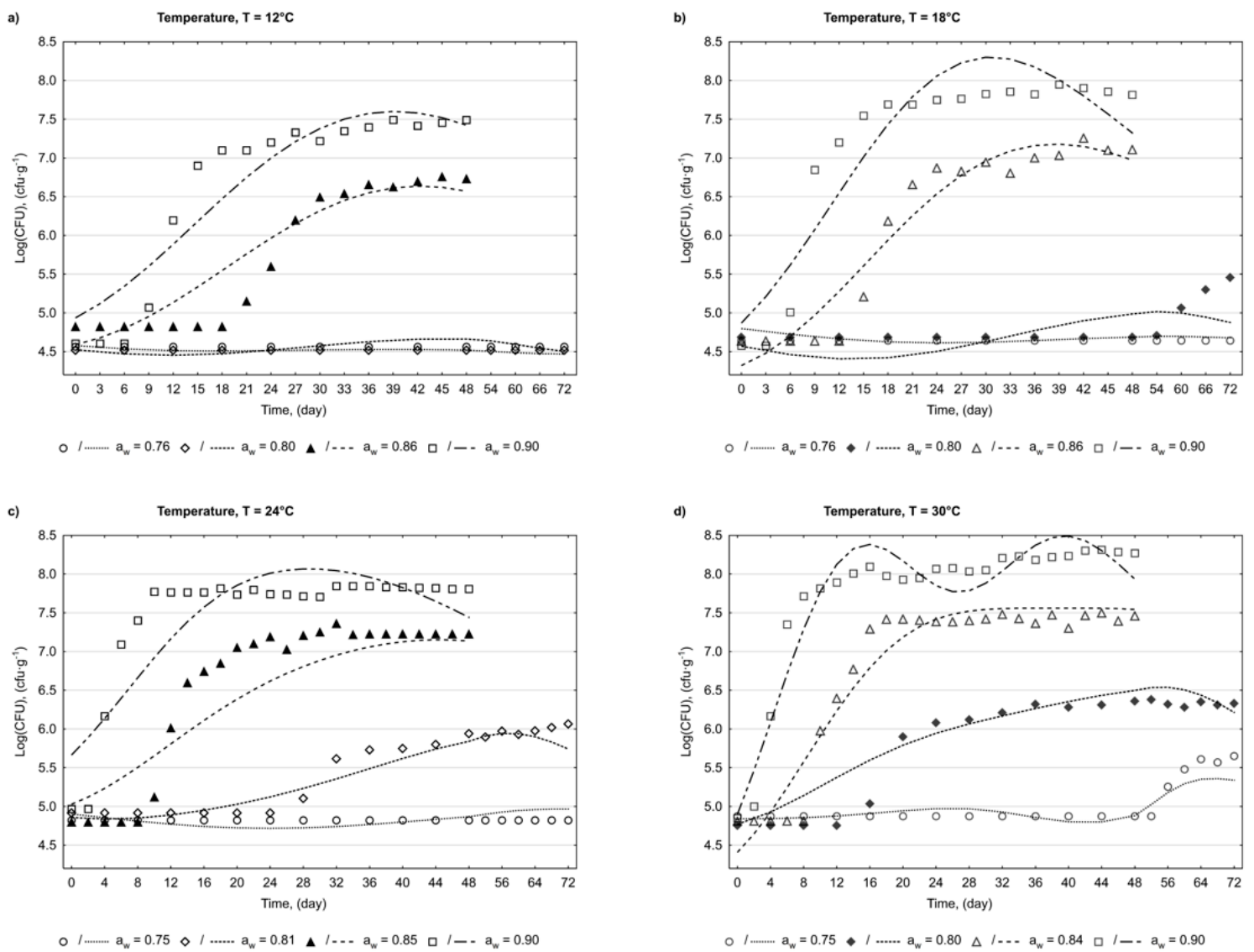

Figure 6. The comparison of RBF neural network model predictions (model lines) and observed mold population levels $(\log (\mathrm{CFU}))$ (experimental points) in rapeseed ecosystems with water activity $\mathrm{a}_{\mathrm{w}}=$ 0.75-0.90 stored at: (a) $12{ }^{\circ} \mathrm{C}$, (b) $18{ }^{\circ} \mathrm{C}$, (c) $24{ }^{\circ} \mathrm{C}$, (d) $30{ }^{\circ} \mathrm{C}$ adopted from Wawrzyniak et al. [6] as a function of time (empty points - data used to model construction, filled points - validation data sets).

The superiority of the MLP-NNM $\mathrm{MC}_{\mathrm{C}}$ fitting performance is also noticeable in Figures 7 and 8 presenting a comparison of the experimental data with estimates of the MLP-NNM $M_{M C}\left(R^{2}=0.969-0.993\right)$ and the RBF-NNM $\mathrm{MC}_{\mathrm{C}}\left(\mathrm{R}^{2}=0.893-0.967\right)$.

The direction for the deviations of the estimated values in relation to the fungal population levels measured experimentally was determined using two bias indexes. One of them was the bias factor, which provides information on the average distinction between the model responses and experimental data. When the model underestimates, the value of the bias factor is below unity, in the opposite case, the model tends to overestimate the experimental values [46]. In this study, the values of $\mathrm{B}_{\mathrm{f}}$ obtained for both selected neural network models showed that the positive and negative deviations of models were on average equal. Its values calculated for all the data sets in the case of both models $\left(\mathrm{B}_{\mathrm{f}}=0.99-1.00\right)$ were in the range of $0.90-1.05$, which is defined as relevant for good predictive models [46]. In the case of MRPE (the second bias index), a positive value designates the underestimation of the outputs of the model, whereas overestimation of the predictions is indicated by its negative value. In this study, the MRPE values calculated for both selected networks were within a narrow range around zero indicating, similarly to the $B_{\mathrm{f}}$ values, a negligible mean divergence between the model responses and observed data. 

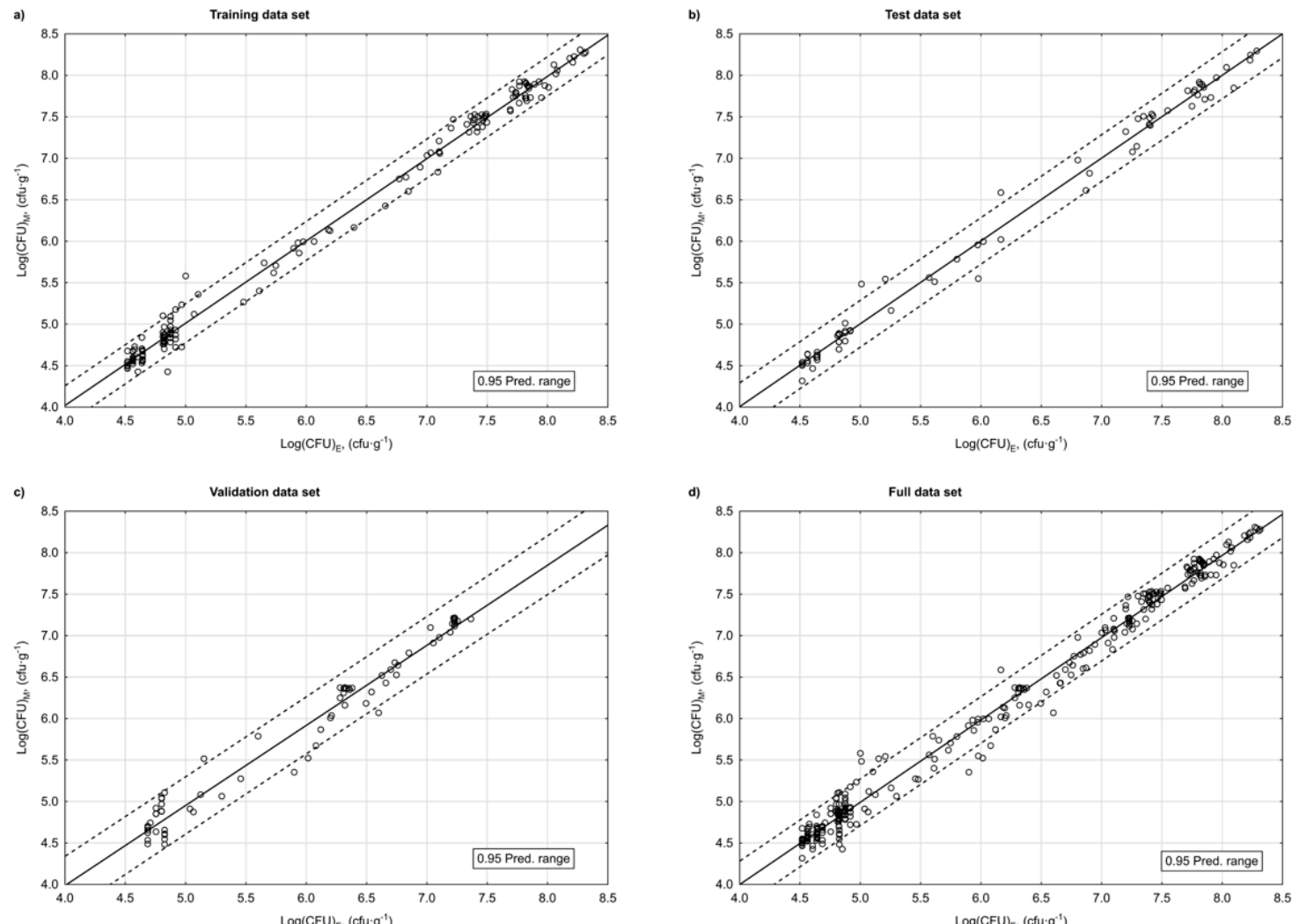

Figure 7. Levels of mold contamination in rapeseed ecosystems with water activity $\mathrm{a}_{\mathrm{w}}=0.75-0.90$ stored at $12-30{ }^{\circ} \mathrm{C}$ predicted by the MLP neural network model $\left(\log (\mathrm{CFU})_{\mathrm{M}}\right.$ against experimental levels of the fungal population $\left(\log (\mathrm{CFU})_{\mathrm{E}}\right)$ adopted from Wawrzyniak et al. [6] for (a) training, (b) test, (c) validation, and (d) full data sets.

It should be emphasized that the MRPE value of zero and the $B_{f}$ value of one do not exclude the presence of divergence between predictions and observations, as positive and negative deviations may be canceled when calculating their values. Therefore, to determine the magnitude of average deviation of the model responses in relation to the experimental data two other indices, such as $A_{f}$ and MAPE, were used. The $A_{f}$ informs on the percentage of error in the model estimates and predictive microbiology it is often used together with $B_{f}$ to evaluate the model performance $[25,26,33]$. The value of $A_{f}$ close to one confirms the high accuracy of the model and the low value of the model prediction error [53]. In this study, the $A_{f}$ was in the range of 1.01-1.03 for MLP-NNM ${ }_{M C}$ and 1.03-1.05 for RBF-NNM $\mathrm{MC}_{\mathrm{C}}$, suggesting respectively a maximum of $3 \%$ and $5 \%$ average deviation of the measured and predicted values. These values were consistent with another accuracy indicator, i.e., MAPE. Its values calculated for the analyzed data sets indicated the $1.5-2.5 \%$ and $2.8-4.7 \%$ error in the MLP-NNM $M_{M C}$ and the RBF-NNM $M_{M C}$ predictions, respectively. Similar percentage errors were obtained by Panagou and Kodogiannis [33] for neural network models describing the dependence between the maximum specific growth rate of $M$. ruber and environmental conditions.

The evaluation of the produced neural network models showed that MLP-NNM $\mathrm{MC}_{\mathrm{C}}$ provided a better predictive efficiency than the RBF-NN $\mathrm{N}_{\mathrm{MC}}$; nevertheless, even the results obtained for the RBF-NNM $M_{M C}$ indicate that its predictive performance (Table 4) is comparable to those obtained for the kinetic model based on the modified Gompertz equation $\left(\mathrm{R}^{2}=0.893, \mathrm{RMSE}=0.547, \mathrm{~B}_{\mathrm{f}}=1.045\right.$, $\mathrm{A}_{\mathrm{f}}=1.050$ for an independent experimental data set) [54] formulated previously on the same data by Wawrzyniak et al. [6]. It is worth mentioning that due to the modeling assumptions, the scope of the kinetic model of mold growth developed with the use of the modified Gompertz equation is limited to the rapeseed storage conditions, in which the fungal growth curves fully follow the sigmoidal pattern. 
These make it of limited utility compared to the neural network models that cover the entire considered area of temperature and water activity applied in stored bulks of seeds. The earlier research released that the neural network model provided better results than the mathematical model based on logistic regression in classifying the growth boundaries of Listeria monocytogenes [30]. The prediction accuracy attained with the RBF and MLP neural network also turned out to be better than those obtained with the classical polynomial models when modeling the kinetic parameters of M. ruber in relation to temperature, water activity, and $\mathrm{pH}[32,33]$.
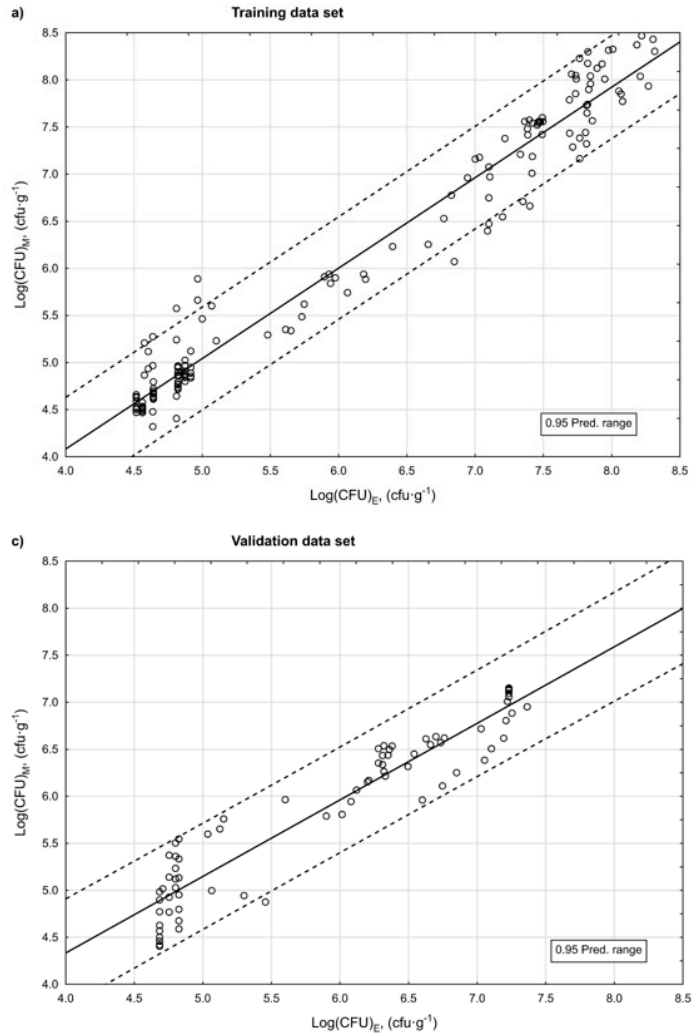
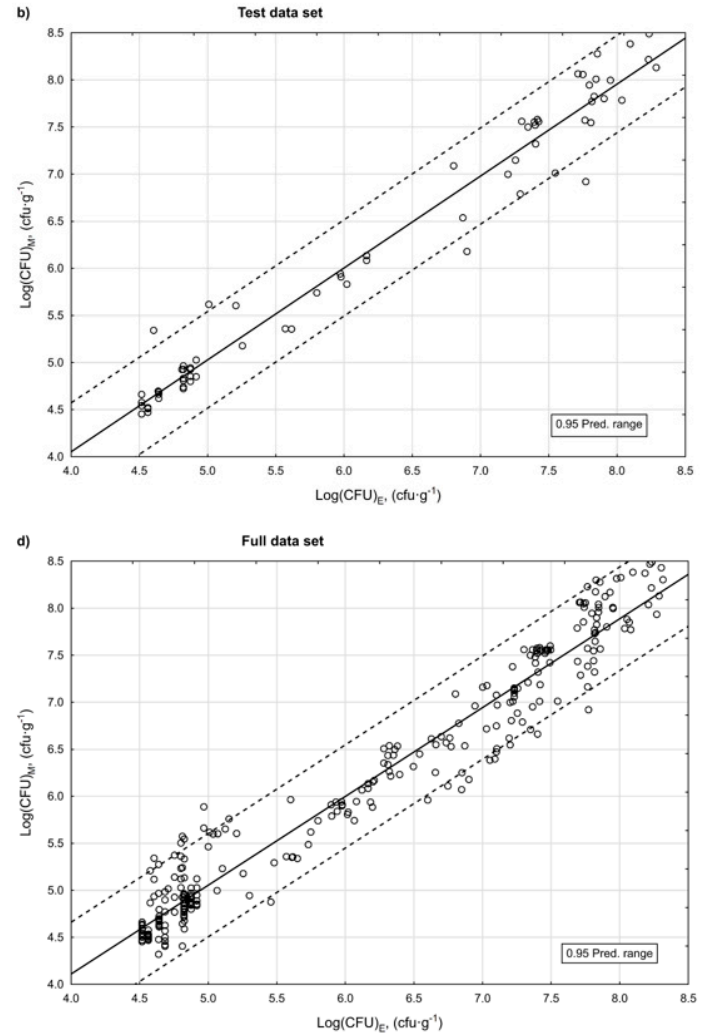

Figure 8. Levels of mold contamination in rapeseed ecosystems with water activity $\mathrm{a}_{\mathrm{w}}=0.75-0.90$ stored at $12-30{ }^{\circ} \mathrm{C}$ predicted by the RBF neural network model $\left(\log (\mathrm{CFU})_{\mathrm{M}}\right.$ against experimental levels of the fungal population $\left(\log (\mathrm{CFU})_{\mathrm{E}}\right.$ ) adopted from Wawrzyniak et al. [6] for (a) training, (b) test, (c) validation, and (d) full data sets.

The study showed that artificial networks can be effectively applied as the modeling technique in predictive mycology. The satisfactory accuracy and precision of the developed MLP-NNM $\mathrm{MC}_{\mathrm{MC}}$ indicate that it may find application in rapeseed postharvest management systems as a supportive tool. The fact that the model was developed for seeds contaminated with a relatively high initial level of fungal propagules, which may be found in years with high rainfall during seed maturation or harvesting increases the safety of the model application. In further research, the author intends to apply the developed model for other rapeseed varieties and then use it as an assisting decisive tool in the control of the postharvest preservation process of rapeseeds.

\section{Conclusions}

The application of artificial neural networks seems to be a promising approach that may be used in developing decision support tools dedicated to agricultural postharvest systems. This is confirmed by the results of this study, in which the artificial neural networks were used to predict fungal population levels over time in a bulk of stored rapeseeds under a wide range of environmental conditions covering those that may be found in agricultural practice. The ANN model based on MLP with a single 
hidden layer containing twelve hidden neurons with the Tanh/Lin activation functions turned out to provide the best architecture to approximate the fungal population level in a bulk of stored rapeseeds. The produced neural network model of mold contamination in a bulk of stored rapeseeds showed high accuracy of the predicted fungal population levels as well as high generalization capability. The fact that it is based on parameters easily measurable on-line in practice, i.e., storage temperature and water activity in seeds, which are the most crucial environmental factors influencing the mycological state of rapeseed ecosystems contributes to increasing the usability of the model. As the model was constructed for seeds characterized by an increased initial contamination with mold spores, its use provides a high margin of safety also in years characterized by difficult ripening and harvesting conditions. The constructed ANN model may be a useful tool that can be explored in the field of agriculture engineering to improve the existing postharvest systems. Incorporation of such forecasting tools into postharvest systems will allow estimating in advance the hazards associated with fungal development and mycotoxin accumulation in a bulk of stored rapeseeds and thus facilitate prevention actions early enough to maintain seed quality.

Funding: This research was partially funded by the Polish Ministry of Science and Higher Education, grant number N N313 209938.

Conflicts of Interest: The author declares that there is no conflict of interest.

\section{References}

1. Wawrzyniak, J.; Gawrysiak-Witulska, M.; Rudzińska, M. Dynamics of phytosterol degradation in a bulk of rapeseed stored under different temperature and humidity conditions. J. Stored Prod. Res. 2019, 83, 292-304. [CrossRef]

2. Siger, A.; Gawrysiak-Witulska, M.; Wawrzyniak, J. Changes in contents of phenolic compounds (sinapic acid derivatives) in seeds of Brassica napus L. under adverse storage conditions. Acta Sci. Pol. Technol. Aliment. 2018, 17, 367-375. [PubMed]

3. Gawrysiak-Witulska, M.; Siger, A.; Wawrzyniak, J.; Nogala-Kalucka, M. Changes in tocochromanol content in seeds of Brassica napus L. during Adverse conditions of storage. J. Am. Oil Chem. Soc. 2011, 88, 1379-1385. [CrossRef]

4. Sun, K.; Jian, F.; Jayas, D.S.; White, N.D.G. Quality changes in high and low oil content canola during storage: Part I-Safe storage time under constant temperatures. J. Stored Prod. Res. 2014, 59, 320-327. [CrossRef]

5. Senthilkumar, T.; Jayas, D.S.; White, N.D.G. Detection of different stages of fungal infection in stored canola using near-infrared hyperspectral imaging. J. Stored Prod. Res. 2015, 63, 80-88. [CrossRef]

6. Wawrzyniak, J.; Gawrysiak-Witulska, M.; Ryniecki, A. Management control points related to the lag phase of fungal growth in a stored rapeseed ecosystem. J. Am. Oil Chem. Soc. 2018, 95, 1223-1235. [CrossRef]

7. Sujith Kumar, M.S.; Mawlong, I.; Singh, D. Phytosterol recovery from oilseeds: Recent advances. J. Food Process Eng. 2017, 40, e12466. [CrossRef]

8. Bhat, R.; Reddy, K.R.N. Challenges and issues concerning mycotoxins contamination in oil seeds and their edible oils: Updates from last decade. Food Chem. 2017, 215, 425-437. [CrossRef]

9. Gancarz, M.; Wawrzyniak, J.; Gawrysiak-Witulska, M.; Wiącek, D.; Nawrocka, A.; Tadla, M.; Rusinek, R. Application of electronic nose with MOS sensors to prediction of rapeseed quality. Measurement 2017, 103, 227-234. [CrossRef]

10. Gancarz, M.; Wawrzyniak, J.; Gawrysiak-Witulska, M.; Wiącek, D.; Nawrocka, A.; Rusinek, R. Electronic nose with polymer-composite sensors for monitoring fungal deterioration of stored rapeseed. Int. Agrophys. 2017, 31, 317-325. [CrossRef]

11. Kogkaki, E.A.; Sofoulis, M.; Natskoulis, P.; Tarantilis, P.A.; Pappas, C.S.; Panagou, E.Z. Differentiation and identification of grape-associated black aspergilli using Fourier transform infrared (FT-IR) spectroscopic analysis of mycelia. Int. J. Food Microbiol. 2017, 259, 22-28. [CrossRef] [PubMed]

12. Marks, B.P. Status of microbial modeling in food process models. Compr. Rev. Food Sci. Food Saf. 2008, 7, 137-143. [CrossRef] 
13. Natskoulis, P.I.; Panagou, E.Z. Predictive modelling of Aspergillus flavus growth and aflatoxins production. In Aflatoxins: Biochemistry, Toxicology, Public Health, Policies and Modern Methods of Analysis; Kintzios, S., Mavrikou, S., Eds.; Nova Science Publishers Inc.: Hauppauge, NY, USA, 2020; pp. 157-206. ISBN 978-1-53616-785-6.

14. Zwietering, M.H.; Jongenburger, I.; Rombouts, F.M.; Van't Riet, K. Modeling of the bacterial growth curve. Appl. Environ. Microbiol. 1990, 56, 1875-1881. [CrossRef] [PubMed]

15. Baranyi, J.; Roberts, T.A. A dynamic approach to predicting bacterial growth in food. Int. J. Food Microbiol. 1994, 23, 277-294. [CrossRef]

16. Przybył, K.; Gawałek, J.; Koszela, K.; Wawrzyniak, J.; Gierz, L. Artificial neural networks and electron microscopy to evaluate the quality of fruit and vegetable spray-dried powders. Case study: Strawberry powder. Comput. Electron. Agric. 2018, 155, 314-323. [CrossRef]

17. Kaya, E.; Saritas, İ. Towards a real-time sorting system: Identification of vitreous durum wheat kernels using ANN based on their morphological, colour, wavelet and gaborlet features. Comput. Electron. Agric. 2019, 166, 105016. [CrossRef]

18. Nasirahmadi, A.; Behroozi-Khazaei, N. Identification of bean varieties according to color features using artificial neural network. Span. J. Agric. Res. 2013, 11, 670-677. [CrossRef]

19. Behroozi Khazaei, N.; Tavakoli, T.; Ghassemian, H.; Khoshtaghaza, M.H.; Banakar, A. Applied machine vision and artificial neural network for modeling and controlling of the grape drying process. Comput. Electron. Agric. 2013, 98, 205-213. [CrossRef]

20. Cinar, I.; Koklu, M. Classification of Rice Varieties Using Artificial Intelligence Methods. Int. J. Intell. Syst. Appl. Eng. 2019, 7, 188-194. [CrossRef]

21. Ali, S.S.E.; Dildar, S.A. An Efficient Quality Inspection of Food Products Using Neural Network Classification. J. Intell. Syst. 2020, 29, 1425-1440. [CrossRef]

22. Gu, S.; Wang, J.; Wang, Y. Early discrimination and growth tracking of Aspergillus spp. contamination in rice kernels using electronic nose. Food Chem. 2019, 292, 325-335. [CrossRef] [PubMed]

23. Adiani, V.; Gupta, S.; Ambolikar, R.; Variyar, P.S. Development of rapid method to assess microbial quality of minimally processed pomegranate arils using FTIR. Sens. Actuators B Chem. 2018, 260, 800-807. [CrossRef]

24. Siripatrawan, U.; Makino, Y. Monitoring fungal growth on brown rice grains using rapid and non-destructive hyperspectral imaging. Int. J. Food Microbiol. 2015, 199, 93-100. [CrossRef] [PubMed]

25. Jeyamkondan, S.; Jayas, D.S.; Holley, R.A. Microbial growth modelling with artificial neural networks. Int. J. Food Microbiol. 2001, 64, 343-354. [CrossRef]

26. Ebrahimi, M.; Safari Sinegani, A.A.; Sarikhani, M.R.; Mohammadi, S.A. Comparison of artificial neural network and multivariate regression models for prediction of Azotobacteria population in soil under different land uses. Comput. Electron. Agric. 2017, 140, 409-421. [CrossRef]

27. Alghooneh, A.; Alizadeh Behbahani, B.; Noorbakhsh, H.; Tabatabaei Yazdi, F. Application of intelligent modeling to predict the population dynamics of Pseudomonas aeruginosa in Frankfurter sausage containing Satureja bachtiarica extracts. Microb. Pathog. 2015, 85, 58-65. [CrossRef]

28. Amina, M.; Kodogiannis, V.S.; Petrounias, I.P.; Lygouras, J.N.; Nychas, G.-J.E. Identification of the Listeria monocytogenes survival curves in UHT whole milk utilising local linear wavelet neural networks. Expert Syst. Appl. 2012, 39, 1435-1450. [CrossRef]

29. Keeratipibul, S.; Phewpan, A.; Lursinsap, C. Prediction of coliforms and Escherichia coli on tomato fruits and lettuce leaves after sanitizing by using Artificial Neural Networks. LWT_Food Sci. Technol. 2011, 44, 130-138. [CrossRef]

30. Valero, A.; Hervás, C.; García-Gimeno, R.M.; Zurera, G. Product unit neural network models for predicting the growth limits of Listeria monocytogenes. Food Microbiol. 2007, 24, 452-464. [CrossRef]

31. Yu, C.; Davidson, V.J.; Yang, S.X. A neural network approach to predict survival/death and growth/no-growth interfaces for Escherichia coli O157:H7. Food Microbiol. 2006, 23, 552-560. [CrossRef]

32. Panagou, E.Z.; Kodogiannis, V.; Nychas, G.J.E. Modelling fungal growth using radial basis function neural networks: The case of the ascomycetous fungus Monascus ruber van Tieghem. Int. J. Food Microbiol. 2007, 117, 276-286. [CrossRef] [PubMed]

33. Panagou, E.Z.; Kodogiannis, V.S. Application of neural networks as a non-linear modelling technique in food mycology. Expert Syst. Appl. 2009, 36, 121-131. [CrossRef] 
34. Mateo, F.; Gadea, R.; Medina, Á.; Mateo, R.; Jiménez, M. Predictive assessment of ochratoxin A accumulation in grape juice based-medium by Aspergillus carbonarius using neural networks. J. Appl. Microbiol. 2009, 107, 915-927. [CrossRef] [PubMed]

35. Mateo, F.; Gadea, R.; Mateo, E.M.; Jiménez, M. Multilayer perceptron neural networks and radial-basis function networks as tools to forecast accumulation of deoxynivalenol in barley seeds contaminated with Fusarium culmorum. Food Control 2011, 22, 88-95. [CrossRef]

36. Aldars-García, L.; Sanchis, V.; Ramos, A.J.; Marín, S. Single vs multiple-spore inoculum effect on growth kinetic parameters and modeled probabilities of growth and aflatoxin B1 production of Aspergillus flavus on pistachio extract agar. Int. J. Food Microbiol. 2017, 243, 28-35. [CrossRef]

37. Marín, S.; Cuevas, D.; Ramos, A.J.; Sanchis, V. Fitting of colony diameter and ergosterol as indicators of food borne mould growth to known growth models in solid medium. Int. J. Food Microbiol. 2008, 121, 139-149. [CrossRef]

38. Yogendrarajah, P.; Vermeulen, A.; Jacxsens, L.; Mavromichali, E.; De Saeger, S.; De Meulenaer, B.; Devlieghere, F. Mycotoxin production and predictive modelling kinetics on the growth of Aspergillus flavus and Aspergillus parasiticus isolates in whole black peppercorns (Piper nigrum L.). Int. J. Food Microbiol. 2016, 228, 44-57. [CrossRef]

39. Garcia, D.; Ramos, A.J.; Sanchis, V.; Marín, S. Predicting mycotoxins in foods: A review. Food Microbiol. 2009, 26, 757-769. [CrossRef]

40. Magan, N.; Aldred, D. Post-harvest control strategies: Minimizing mycotoxins in the food chain. Int. J. Food Microbiol. 2007, 119, 131-139. [CrossRef]

41. Mylona, K.; Magan, N. Fusarium langsethiae: Storage environment in fluences dry matter losses and T2 and HT-2 toxin contamination of oats. J. Stored Prod. Res. 2011, 47, 321-327. [CrossRef]

42. Huang, Y.; Lan, Y.; Thomson, S.J.; Fang, A.; Hoffmann, W.C.; Lacey, R.E. Development of soft computing and applications in agricultural and biological engineering. Comput. Electron. Agric. 2010, 71, 107-127. [CrossRef]

43. Sánchez, R.J.; Fernández, M.B.; Nolasco, S.M. Artificial neural network model for the kinetics of canola oil extraction for different seed samples and pretreatments. J. Food Process Eng. 2018, 41, e12608. [CrossRef]

44. López-Aguilar, K.; Benavides-Mendoza, A.; González-Morales, S.; Juárez-Maldonado, A.; Chiñas-Sánchez, P.; Morelos-Moreno, A. Artificial neural network modeling of greenhouse tomato yield and aerial dry matter. Agriculture 2020, 10, 97. [CrossRef]

45. Mittal, G.S. Artificial Neural Network (ANN) Based Process Modeling. In Handbook of Farm, Dairy and Food Machinery Engineering, 2nd ed.; Kutz, M., Ed.; Academic Press: Cambridge, MA, USA; Elsevier Inc.: Amsterdam, The Netherlands, 2013; pp. 467-473. ISBN 9780123858818.

46. Te Giffel, M.C.; Zwietering, M.H. Validation of predictive models describing the growth of Listeria monocytogenes. Int. J. Food Microbiol. 1999, 46, 135-149. [CrossRef]

47. Walther, B.A.; Moore, J.L. The concepts of bias, precision and accuracy, and their use in testing the performance of species richness estimators, with a literature review of estimator performance. Ecography 2005, 28, 815-829. [CrossRef]

48. Du, C.J.; Sun, D.W. Learning techniques used in computer vision for food quality evaluation: A review. J. Food Eng. 2006, 72, 39-55. [CrossRef]

49. Sheela, K.G.; Deepa, S.N. Selection of number of hidden neurons in neural networks in renewable energy systems. J. Sci. Ind. Res. 2014, 73, 686-688.

50. Fernández, J.C.; Hervás, C.; Martínez-Estudillo, F.J.; Gutiérrez, P.A. Memetic Pareto Evolutionary Artificial Neural Networks to determine growth/no-growth in predictive microbiology. Appl. Soft Comput. 2011, 11, 534-550. [CrossRef]

51. Cybenko, G. Approximation by superpositions of a sigmoidal function. Math. Control Signals Syst. 1989, 2, 303-314. [CrossRef]

52. Huang, Y. Advances in artificial neural networks-Methodological development and application. Algorithms 2009, 2, 973-1007. [CrossRef]

53. Zimmermann, M.; Miorelli, S.; Massaguer, P.R.; Falcão Aragão, G.M. Modeling the influence of water activity and ascospore age on the growth of Neosartorya fischeri in pineapple juice. LWT Food Sci. Technol. 2011, 44, 239-243. [CrossRef] 
54. Wawrzyniak, J. A Predictive Model for Assessment of the Risk of Mold Growth in Rapeseeds Stored in a bulk as a Decision Support Tool for Postharvest Management Systems. J. Am. Oil Chem. Soc. 2020. [CrossRef]

Publisher's Note: MDPI stays neutral with regard to jurisdictional claims in published maps and institutional affiliations.

(C) 2020 by the author. Licensee MDPI, Basel, Switzerland. This article is an open access article distributed under the terms and conditions of the Creative Commons Attribution (CC BY) license (http://creativecommons.org/licenses/by/4.0/). 